\title{
Response to "Total hip arthroplasty for active tuberculosis of the hip"
}

\author{
Arun Pal Singh $\cdot$ Ajay Pal Singh $\cdot$ Surbhi Mahajan
}

Received: 21 August 2009 /Accepted: 6 September 2009 /Published online: 25 September 2009

(C) Springer-Verlag 2009

We read with interest article "Total hip arthroplasty for active tuberculosis of the hip" by Wang et al. [1]. We would like to commend the authors for their work and would like to raise some queries.

The authors assessed preoperative erythrocyte sedimentation rate. It would be interesting to know whether they measured C-reactive protein values. In two patients with sinus, was the sinus communicating with the hip joint, and if so, was a preoperative sinogram done? It is inadvisable to operate on patients with discharging sinus, as incomplete debridement may result with a higher rate of reactivation [2-4]. What precautions do the authors advise in such cases? The literature recommends preoperative chemotherapy for three weeks to two months [3, 4]. Therefore, why did the authors choose a limit of two weeks? Was it set arbitrarily, or was there some scientific basis? Also, cemented arthroplasty was performed in two cases and cementless in four. How were the patients selected for either surgery? If the patients were already on antitubercular treatment (ATT), why were rifampicin and streptomycin used for local wash? Do they have any added benefit? Immediate weightbearing can be allowed in cemented arthroplasty. Why was this delayed in this series? Finally, all patients received chemotherapy for 12 months, except for patient six who received it for 18 months. What was the reason for prolongation of treatment in this case?

\section{References}

1. Wang Y, Wang J, Xu Z, Li Y, Wang H (2009) Total hip arthroplasty for active tuberculosis of the hip. Int Orthop. Aug 15. doi:10.1007/ s00264-009-0854-6.

2. Yoon TR, Rowe SM, Santosa SB, Jung ST, Seon JK (2005) Immediate cementless total hip arthroplasty for the treatment of active tuberculosis. J Arthroplasty 20:923-926

3. Caparros AB, Sousa M, Ribera ZJ, Uceda CP, Moya CF (1999) Total hip arthroplasty for tuberculous coxitis. Int Orthop 23 (6):348-350

4. Kim YY, Ko CU, Ahn JY, Yoon YS, Kwak BM (1988) Charnley low-friction arthroplasty in tuberculosis of the hip. An 8- to 13-year follow-up. J Bone Joint Surg Br 70(5):756-760
A. P. Singh $\cdot$ A. P. Singh $(\bowtie)$

Department of Orthopaedics, UCMS \& GTB Hospital,

D-13. Residential Complex, GTB Campus, Dilshad Garden,

Delhi, India

e-mail: Docajaypal@gmail.com

\section{S. Mahajan}

Department of Pathology, UCMS \& GTB Hospital,

Dilshad Garden,

Delhi, India 